\title{
Effect of Physisporinus vitreus on wood properties of Norway spruce. Part 1: Aspects of delignification and surface hardness
}

\author{
Christian Lehringer ${ }^{1, *}$, Gerald Koch $^{2}$, \\ Ramesh-Babu Adusumalli ${ }^{3}$, William M. Mook $^{3}$, \\ Klaus Richter ${ }^{1}$ and Holger Militz ${ }^{4}$ \\ ${ }^{1}$ Empa - Swiss Federal Laboratories for Materials Science \\ and Technology, Wood Laboratory, Dübendorf, \\ Switzerland \\ ${ }^{2}$ Institute of Wood Technology and Wood Biology, Federal \\ Research Institute for Rural Areas, Forestry and Fisheries, \\ Hamburg, Germany \\ ${ }^{3}$ Empa - Swiss Federal Laboratories for Materials Science \\ and Technology, Mechanics of Materials and \\ Nanostructures, Thun, Switzerland \\ ${ }^{4}$ Wood Biology and Wood Products, Burckhardt-Institute, \\ Georg-August-University, Göttingen, Germany \\ * Corresponding author. \\ Empa - Swiss Federal Laboratories for Materials Science \\ and Technology, Wood Laboratory, \\ Dübendorf, Switzerland \\ E-mail: christian.lehringer@empa.ch
}

\begin{abstract}
The white rot fungus Physisporinus vitreus is currently tested for several biotechnological applications such as permeability improvement of refractory wood species or the optimization of the acoustic properties of wood for violins. The enzymatic activity of $P$. vitreus results in the degradation of pit membranes and simultaneous alterations of the tracheid cell wall structure in wood of Norway spruce [Picea abies (L.) Karst]. By this means, selective delignification and simultaneous degradation occur in the latewood tracheids at short incubation times. To study the delignification of individual cell wall layers in latewood tracheids, cellular UVmicrospectrophotometry was applied to wood of Norway spruce that had been incubated for between 3 and 9 weeks. By means of this technique, the progressing delignification was demonstrated in the latewood tracheid secondary walls. Moreover, local delignification in close proximity to hyphal tunneling, cavities, and notches was evident. Additionally, the mechanical changes were measured (a) at the macroscopic level by Brinell hardness test and (b) at the cellular level by nanoindentation. Brinell hardness was significantly reduced with increasing incubation time which was attributed to the partial delignification. Unlike Brinell tests, results from nanoindentation tests did not show a clear effect of fungal activity because of the material heterogeneity and the high spatial resolution of this technique. The present study provides methodological approaches for the investigation of wood-fungus interactions and contributes to a better under-
\end{abstract}

standing of the characteristics of wood decay at the subcellular level caused by the white rot fungus $P$. vitreus. Moreover, it establishes the basis for a subsequent chemical analysis, for which the results will be the topic of a second paper in this series.

Keywords: Brinell hardness; delignification; nanoindentation; UV-microspectrophotometry (UMSP); wood decay.

\section{Introduction}

Wood decay fungi in biotechnological applications have been studied for more than 30 years. In the pulp and paper industry, white rot fungi are successfully applied in bio-pulping or bio-bleaching of Kraft pulp (Mai et al. 2004). In the context of wood technological tasks, fungi are able to modify specific properties of wood. During the early 1960s, the use of "Myco-wood" for pencil production was industrially conducted in the German Democratic Republic (Unbehaun et al. 2000). More recently, the white rot fungus Physisporinus vitreus was tested for improvement of acoustic properties of wood for violins (Schwarze et al. 2008) or permeability improvement ("bioincising') of Norway spruce (Schwarze et al. 2006; Lehringer et al. 2009). In these cases, homogeneous and rapid wood colonization and a controlled activity of the wood decay fungus are required to ensure a high and reproducible product quality within economically acceptable periods of time. Moreover, the surface of the treated wood must have an aesthetic appearance and its mechanical properties should not be weakened.

Schwarze et al. (2006) investigated the wood properties of Norway spruce heartwood that had been incubated with $P$. vitreus for 6 weeks. They found no significant reduction in impact bending strength. However, microscopic studies revealed morphological changes due to fungal activity, and simultaneous degradation of pit membranes and tracheid cell walls were observed even at early stages of substrate colonization (Lehringer et al. 2010). In the same study, selective delignification and simultaneous degradation of lignin and polysaccharides were observed corresponding to the characteristics of white rot and soft rot type I and type II. The term selective delignification means a successive decomposition of the cell wall components: the degradation of lignin and hemicelluloses occur preferably at the beginning of fungal colonization, whereas the cellulose fraction is degraded later (Liese 1970). Simultaneous rot is characterized by fungal ecto-enzymes which have the capacity to degrade cellulose, hemicelluloses, and lignin at the same time (Schmidt 2006). 
In these processes, at least two different enzymatic mechanisms are involved. White rot is based on a lignolytic system that brings about preferential lignin and hemicelluloses depolymerization at larger distances from fungal hyphae (Blanchette et al. 1985). Soft rot is characterized by the formation of narrow erosion cavities and hyphal tunneling that implies the presence of enzymes with a very low diffusibility (Blanchette et al. 1985). Kleist and Schmitt (2001) also found that the lignolytic activity was restricted to a very close vicinity of the areas of hyphal tunneling in the case if decay was caused by brown rot and soft rot in wood of Sapeli (Entandrophragma cylindricum Sprague).

Owing to the fungal activity occurring close to the surface, the surface hardness can decrease whereas the overall strength properties are not significantly affected. The mechanical integrity of the surface plays a key role, if high quality wood is required (e.g., violin wood, flooring). Hence, the effects of these alterations have to be investigated in detail.

The impact of wood decay fungi on mechanical properties of wood has been described in many studies (Morrell and Zabel 1985; Kim et al. 2005; Schmidt 2006). The surface hardness is strongly associated with cell wall density and with the lignin content of the cell wall matrix. Accordingly, cellular UV-microspectrophotometry (UMSP) was applied to characterize the delignification process of $P$. vitreus on Norway spruce after incubation times of up to 9 weeks. The UMSP technique is well suitable for detecting the topochemical distribution of lignin at a subcellular level (Koch and Kleist 2001; Irbe et al. 2006; Kim et al. 2008; Lehringer et al. 2008; Prislan et al. 2009). Bauch et al. (1976) applied UMSP successfully to investigate topochemical delignification caused by fungal decay in woody tissue. Kleist and Seehann (1997) described effects of fungal activity in latewood regions of Norway spruce wood after 8 weeks incubation with white rot fungus Stereum sanguinolentum. Lower lignin contents caused by fungal delignification result in lower absorbances at $280 \mathrm{~nm}$. Moreover, the local delignification around hyphal tunneling, cavities, and notches in the tracheid cell walls can be visualized by field imaging.

Surface hardness measurements according to the Brinell test method were performed, as this method is a sensitive indicator for chemical and morphological changes caused by wood decaying fungi (Rypacek 1966). Lignin modification (Hakala et al. 2005), lignin removal and the reduction of cell wall thickness due to hyphal tunneling, cavities, and notches result in hardness reduction (Whetten and Sederoff 1995).

Finally, nanoindentation tests were performed. The recorded load-displacement curve and the indentation depth deliver the basis to calculate hardness and the reduced elastic modulus at very high spatial resolution (Oliver and Pharr 2004). Previously, this method has been applied to investigate specific structural and mechanical properties of different wood tissues at the cell wall level (Gindl et al. 2004; Wang et al. 2006; Lee et al. 2007; Konnerth et al. 2009, 2010; Adusumalli et al. 2010; Stöckel et al. 2010).

The principle objective of the present study is to better understand the effect of delignification on the mechanical properties of wood incubated with $P$. vitreus. Topochemical alterations on the tracheid cell walls will be recorded and a correlation to the Brinell hardness will be observed. Moreover, the applicability of the nanoindentation technique on decayed wood should be assessed during short-term incubation times. An in-depth chemical analysis of changes in chemical composition due to fungal activity will follow in a second article of this series (Lehringer et al. 2011).

\section{Material and methods}

\section{Specimen material}

One board of defect-free and klin-dried wood from a Norway spruce tree [Picea abies (L.) Karst] was investigated. For sapwood and heartwood, three specimen collectives were prepared. In each collective, five specimens were always taken in one longitudinal sequence to minimize the influence of natural property variation within the single tree. As the samples were subjected to four different incubation periods and one control, this axial pairing provided a good comparability of the results. Each specimen measured $200 \times 30 \times 30 \mathrm{~mm}^{3}(\mathrm{~L} \times \mathrm{R} \times \mathrm{T})$. Sterilization was done with hot steam at $103^{\circ} \mathrm{C}$ for $2 \mathrm{~h}$; inoculation was done with the white rot fungus $P$. vitreus (microbial strain Empa 642).

The microbial strain of $P$. vitreus was grown on $4 \%$ malt extract agar (MEA) medium (Oxoid, Darmstadt, Germany) in each Petri dish stored at $22^{\circ} \mathrm{C}$ and $70 \%$ relative humidity ( $\left.\mathrm{RH}\right)$. Once a uniform mycelium had formed, $2 \mathrm{~g}$ of steam sterilized Norway spruce sawdust (grain size $4 \mathrm{~mm}$ ) was added to the Petri dishes and the system was left for another 4 weeks at $22^{\circ} \mathrm{C}$ and $70 \%$ RH. Finally, the infected sawdust was collected and brought into a suspension with sterilized water; solid to liquid ratio was $10 \mathrm{~g} \mathrm{l}^{-1}$.

Incubation was performed under sterile conditions by immersing the specimens in this water suspension including sawdust and fungal mycelia. The incubated specimens were then incubated on 1\% MEA and stored for 3, 5, 7, and 9 weeks at $22^{\circ} \mathrm{C}$ and $70 \% \mathrm{RH}$. Each specimen was placed with the tangential surface facing the pith on the nutrient medium (Figure 1). It is not the usual procedure, but the specimens were placed directly on the MEA aiming at rapid initial fungal colonization. After incubation, the mycelium was carefully removed from the surfaces and the specimens were steamsterilized as described above. After drying for $48 \mathrm{~h}$ at $40^{\circ} \mathrm{C}$, the specimens were reconditioned and stored at $20^{\circ} \mathrm{C}$ and $65 \% \mathrm{RH}$. Mass losses were calculated as described by Lehringer et al. (2010).

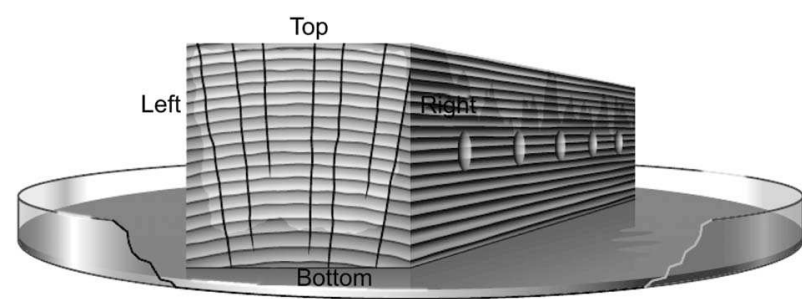

Figure 1 Schematic illustration of incubation of specimens with Physisporinus vitreus in a Petri dish and designation of the surfaces. The darker areas on the wood surfaces indicate zones of higher fungal activity. On the right-hand side is positioning of the Brinell hardness measurements. 


\section{Cellular UV-microspectrophotometry (UMSP)}

For cellular UMSP analyses, small blocks were extracted - of $5 \times 2 \times 2 \mathrm{~mm}^{3}(\mathrm{~L} \times \mathrm{R} \times \mathrm{T})$ from the bottom side of the incubated heartwood specimens - where fungal activity was the strongest. For each incubation time and the control samples, two replicates were made. The specimens were prepared with epoxy resin as embedding medium (Spurr 1969) as described by Kleist and Schmitt (1999). After trimming the embedded specimens, $1 \mu \mathrm{m}$ thin cross-sections were cut on an ultramicrotome Ultracut E (Reichert-Jung, Wetzlar, Germany) equipped with a diamond knife. The sections were transferred to quartz glass slides, thermally fixed at $70^{\circ} \mathrm{C}$ and embedded in glycerine. In these sections, two to three areas of high fungal activity in the latewood tracheids were selected under the light microscope for measuring.

The topochemical analysis was carried out with a UMSP 80 microspectrophotometer (Zeiss, Jena, Germany) equipped with a scanning stage enabling the examination of image profiles at $\lambda=280 \mathrm{~nm}$ that represents the absorbance maximum of softwood lignin (Koch and Kleist 2001). For the field scans, areas of approximately $40 \times 40 \mu \mathrm{m}^{2}$ were scanned line by line using Apamos ${ }^{\circledR}$ software (Zeiss, Jena, Germany). The scan program captures rectangular fields with a local geometric resolution of $0.25 \mu \mathrm{m} \times 0.25 \mu \mathrm{m}$ and yields a photometric resolution of 4096 grayscale levels, which are converted into 14 basic colors to visualize the absorbance intensities. The high resolution enables a differentiation of the UV absorbance within individual cell wall layers, including a histogram of the UV absorbance values. The average absorbance data were extracted for the secondary cell wall regions by setting appropriate filters with Apamos ${ }^{\circledR}$ software. For each specimen, five to seven average spectra were included into the statistical evaluation (resulting in $n=26$ ).

\section{Brinell hardness}

The Brinell hardness was determined five times for each specimen on each radial and tangential surface in a distance of $1.5 \mathrm{~cm}$ from the specimen edges (distance of the measurements: $3.5 \mathrm{~cm}$, Figure 1). Depending on the positioning of the specimen during incubation, the surfaces were designated as top, bottom, left, and right (Figure 1).

Altogether, 600 measurements were performed under standard laboratory climate conditions $\left(20^{\circ} \mathrm{C} / 65 \% \mathrm{RH}\right)$ (Table 1$)$.

A universal Brinell type testing machine (Zwick, Ulm, Germany) with $10 \mathrm{kN}$ load cell and $10 \mathrm{~mm}$ steel indenting ball was applied. The peak load of $500 \mathrm{~N}$ was reached after $15 \mathrm{~s}$, followed by a $30 \mathrm{~s}$ holding time and $15 \mathrm{~s}$ unloading. According to EN 1534 (2000), Brinell hardness is calculated as follows:

$H_{B}=\frac{2 F}{D^{*} \pi^{*}\left(D-\sqrt{D^{2}-d^{2}}\right)}$

where $H_{B}=$ Brinell hardness $\left(\mathrm{N} / \mathrm{mm}^{2}\right), F=\max$. force $(\mathrm{N}), D=$ diameter of steel ball $(\mathrm{mm}), d=$ diameter of intent $(\mathrm{mm})$.

Sonderegger and Niemz (2001) proposed a calculation as differential measurement of indentation depth between wood surface and lowest point of steel ball circumference, i.e., the depth of indentation $h:$

$h=\frac{\left(D-\sqrt{D^{2}-d^{2}}\right)}{2}$.

Brinell hardness was calculated in the present study according to the adapted Eq. (3).
Table 1 Experimental plan for Brinell hardness tests on sapwood (SW) and heartwood (HW).

\begin{tabular}{llc}
\hline \multicolumn{1}{c}{ Description } & \multicolumn{1}{c}{ Variable } & Factor \\
\hline Wood type & $\begin{array}{l}\text { Sapwood (SW), } \\
\text { Heartwood (HW) }\end{array}$ & 2 \\
Collective & A, B, C & 3 \\
Incubation time & $\begin{array}{l}\text { Control, 3, 5, } \\
\text { 7, 9 weeks }\end{array}$ & 5 \\
Side on specimen & $\begin{array}{l}\text { Top, bottom, } \\
\text { right, left } \\
\text { points per side }\end{array}$ & 4 \\
Measurement & Result from factor multiplication: $n=600$ \\
\hline
\end{tabular}

$H_{B}=\frac{F}{D^{*} \pi^{*} \mathrm{~h}}$.

\section{Nanoindentation}

The nanoindentation measurements (Hysitron Ubi nanoindenter, Hysitron Inc., Minneapolis, MN, USA, at ambient room climate) were carried out on the same blocks on which the UMSP measurements were performed. The sample preparation for nanoindentation was performed according to Konnerth et al. (2008). Latewood (LW) tracheids with decayed cell walls were located by light microscopy and the optical microscope of the nanoindenter. On average, 20 indents per sample were placed by visual positioning in the degraded LW tracheid cell walls. Earlywood cell walls were not indented, because cell walls were too thin.

A Berkovich indenter tip, edge length $<150 \mathrm{~nm}$, with three-sided pyramid geometry was used, which was pressed with a determined force into the cell wall cross-section. A maximum load of $250 \mu \mathrm{N}$ was selected for nanoindentation. Loading and unloading speed was $100 \mu \mathrm{N} \mathrm{s}^{-1}$ and the holding time at peak load was $15 \mathrm{~s}$ to monitor the visco-plastic creep. The selected surface regions $\left(40 \times 40 \mu \mathrm{m}^{2}\right)$ were then scanned with normal forces of approximately $200 \mathrm{nN}$ using the indentation tip.

The load-displacement curves obtained from all experiments were evaluated according to the method of Oliver and Pharr (1992). Peak load $\left(P_{\max }\right)$, contact area $(A)$, and initial slope of the unloading curve $(S)$ are the parameters for calculations of the hardness $(H)$ and the reduced modulus of elasticity $\left(E_{r}\right)$ (hereinafter referred as MOE) as shown in Eqs. (4) and (5):

$H=\frac{P_{\max }}{A}$

$E_{r}=\frac{1}{2} \sqrt{\pi} \frac{\mathrm{S}}{\sqrt{\mathrm{A}}}$

The contact area $A$ at $P_{\max }$ was determined from the known shape of the indenter, calibrated by indenting a material with known properties (in this case fused quartz).

\section{Statistical evaluation}

For all collected data, a one-way analysis of variance and a Tukey honesty test were conducted with the statistic software Systat $12^{\circledR}$ (Systat Software Inc., Chicago, IL, USA). A P-value of $<0.05$ was considered statistically significant. 


\section{Results and discussion}

\section{UMSP}

Delignification of individual cell wall layers and in localized regions caused by $P$. vitreus was detected at $280 \mathrm{~nm}$, at which softwood lignins have an absorbance maximum (Figure 2). The color pixels indicate different intensities of the UV absorbance at the respective $\lambda_{\max }$ values. As expected, the UV image profiles of sound spruce tracheids (Figure 2a) are characterized by high absorbance values in the cell corners and in the compound middle lamella $\left(A b s_{280 \mathrm{~nm}}=0.48-0.87\right)$. The absorbance in the secondary cell wall (S2) ranged between $A b s_{280 \mathrm{~nm}}=0.29$ and $A b s_{280 \mathrm{~nm}}=0.48$ and corresponded well to findings of Fergus et al. (1969) who described the average lignin content in the compound middle lamella (CML) being twice as high as that in the adjacent secondary tracheid walls.

Hyphal tunneling within the S2 of LW tracheids, which is commonly considered to be a characteristic of a soft rot type I (Schwarze 2007) is demonstrated in Figure 2c. The presence of hyphal tunneling - characterized by spots with significant lower absorbances - confirms the results from light microscopy investigations (Lehringer et al. 2010). There, selective delignification and simultaneous degradation were found in close proximity to each other. Delignification is limited to a very narrow region around the zone of hyphal growth as indicated clearly by low absorbances around these structures $\left(A b s_{280 \mathrm{~nm}}=0.09-0.22\right)$. The reason for this observation is clear: the lignolytic enzymes do not diffuse deeply into the secondary wall but rather act in close proximity to the hyphae, as also described by Kleist and Schmitt (2001) for brown rot fungi.

Effects of selective delignification are displayed in Figure 2c-e. Additional to the hyphal tunneling, reduced $A b s_{280 \mathrm{~nm}}$ (0.16 and 0.29) are discernable in larger areas of the secondary tracheid cell walls. In this case, P. vitreus depolymerizes lignin and hemicelluloses in the tracheid cell walls from the lumen towards the CML by means of extracellular enzymes and probably also by other coexisting lignolytic systems (Blanchette et al. 1985). By this means, the cell wall shape remains mostly unaltered and the same is true for

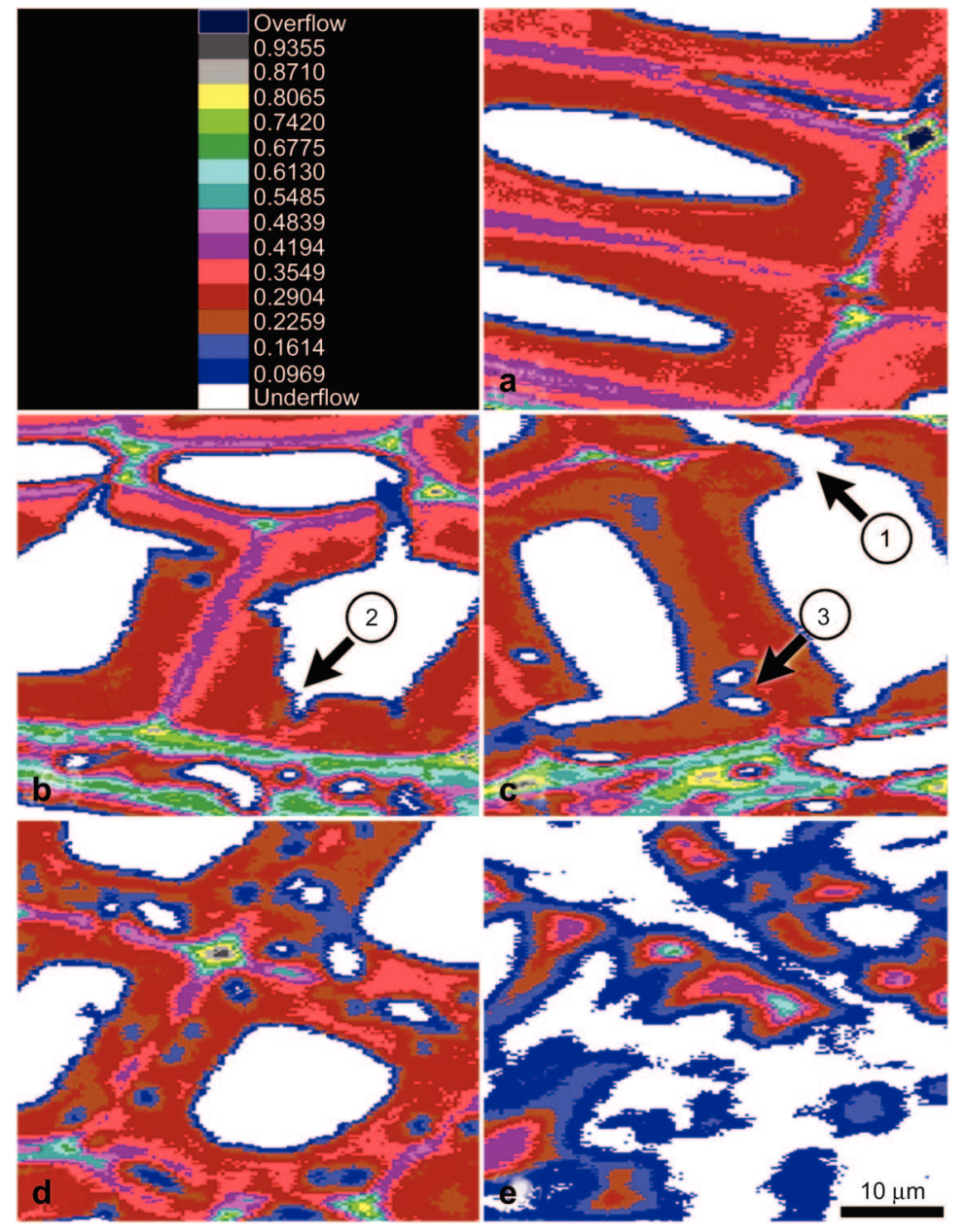

Figure 2 Representative UV microscopic scanning profiles of Norway spruce latewood tracheids after zero (a), 7 (b), 9 (c), 12 (d), and 32 (e) weeks of incubation with Physisporinus vitreus. The color pixels represent different UV absorbances of the cell wall layers at $\lambda=280 \mathrm{~nm}$. Hyphal tunneling (1), notches (2), and cavities (3) can be observed as proof for simultaneous degradation. The progress of selective delignification is visible by lowered absorbances in areas of the secondary cell wall layers. 
the cellulose within the cell wall. However, the CML showed discreet signs of delignification after 7 and 9 weeks incubation.

As an additional source of information, the status after 12 and 32 weeks of incubation is illustrated in Figure 2d,e. Here, the material was incubated with the same method. But the specimens originated from another wood board. This is the reason why the data were only taken for sporadic validation. Nevertheless, the images confirm the observed trend and exemplarily demonstrate the effects of fungal activity at advanced stages of degradation.

The mean UV absorbances showed a decreasing trend as a function of incubation time (Figure 3). Even though the changes are statistically not always significant compared to the control specimen, the trend depicts the expected tendency of increasing delignification with longer incubation times. After 3 and 5 weeks incubation, the decrease of average UV absorbances ranged at $-1.3 \%$ and $-1.9 \%$, respectively. After 7 and 9 weeks incubation time, the values decreased stepwise to $-6 \%$ and $-8.9 \%$, respectively.

The method of UMSP permits to plot discreet changes of mean lignin content even after short-time incubation with the white rot fungi $P$. vitreus. However, the statistical relevance of the data is limited because of the natural variability and increased heterogeneity due to fungal activity.

\section{Brinell hardness}

Heartwood and sapwood The Brinell hardness of the control samples in heartwood and sapwood was $18.1 \mathrm{~N} \mathrm{~mm}^{-2}$ and $18.9 \mathrm{~N} \mathrm{~mm}^{-2}$, respectively (Figure 4, box plots). As differences in Brinell hardness for radial and tangential measurement orientation were negligible, the average values were calculated. Generally, the values for the sapwood specimen were slightly higher than the heartwood specimen. This is due to the fact that the initial density of the sapwood specimens was $3.2 \%$ higher than the heartwood specimens.
The initial density of the sapwood samples was $0.47 \mathrm{~g} \mathrm{~cm}^{-3} \pm$ $4.4 \%$ and of the heartwood samples $0.45 \mathrm{~g} \mathrm{~cm}^{-3} \pm 6.8 \%$.

The first 5 weeks of colonization with $P$. vitreus resulted in a moderate effect on Brinell hardness. The changes of Brinell hardness were not statistically significant neither in sapwood nor in heartwood compared to the control. But after 7 and 9 weeks, the average Brinell hardness was reduced significantly to values between 13.4 and $16.5 \mathrm{~N} \mathrm{~mm}^{-2}$, which indicate a strong increase in fungal activity. Hence, the average decrease of Brinell hardness amounted to $-15.2 \%$ and $-29.9 \%$ for sapwood and $-14.5 \%$ and $-24.1 \%$ for heartwood after 7 and 9 weeks incubation, respectively (Figure 4, line plots).

Lehringer et al. (2010) found similar patterns by light microscopy on the same material. A significantly higher activity of $P$. vitreus was observed after 7 and 9 weeks incubation causing notably more effects on LW tracheid cell walls and pit structures than after 3 or 5 weeks. However, in comparison to other white rot fungi, degradation of the wood matrix remains at a low level even after 9 weeks incubation (see also van Acker and Stevens 1996; Reinprecht et al. 2007). The low mass losses of $2.4 \%$ for heartwood and $2.9 \%$ for sapwood samples validate the relative weak degradation potential of $P$. vitreus during short incubation times.

According to Rypacek (1966), Whetten and Sederoff (1995) and Adusumalli et al. (2010), the removal of lignin results in hardness reduction because lignin as a crosslinking agent is responsible for carrying compression forces within the cell wall and the tissue. Hence, the loss of Brinell hardness can safely be attributed to slight delignification, as shown above by UMSP, and the morphological changes of the tracheid cell walls, as demonstrated by Lehringer et al. (2010).

Spatial heterogeneity The asymmetric supply of nutrients, storage of carbohydrates, water, and oxygen induced a

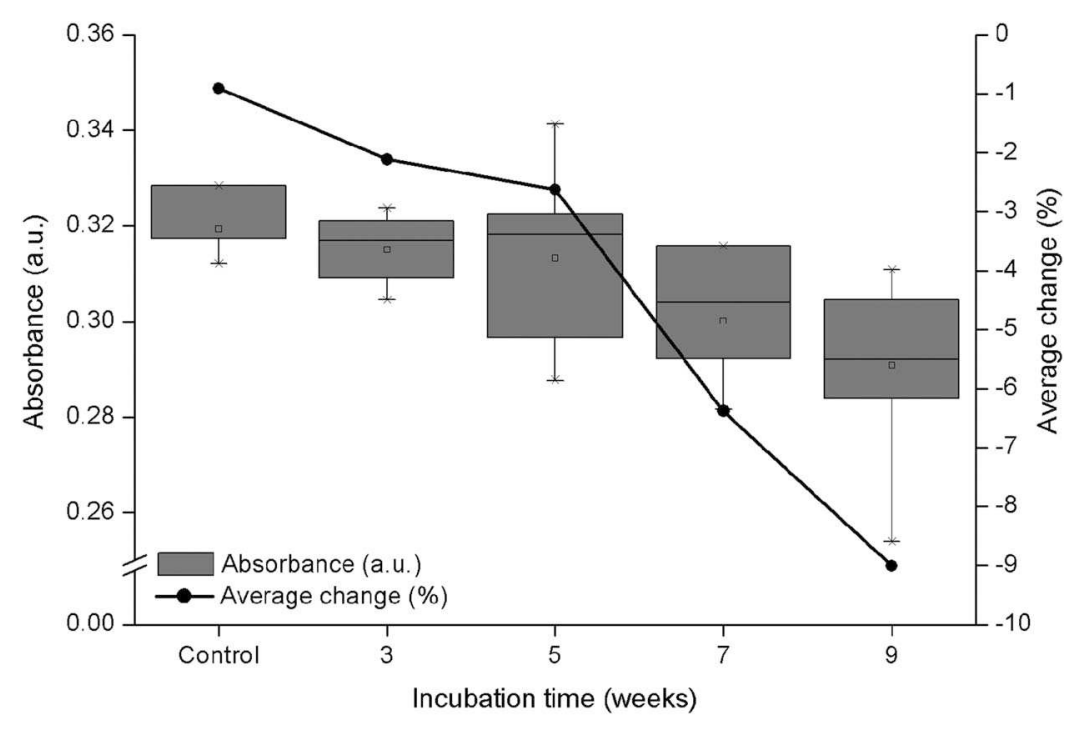

Figure 3 Decreasing UV absorbance at $\lambda=280 \mathrm{~nm}$ in latewood tracheids of Norway spruce after different incubation periods with white rot fungus Physisporinus vitreus. 


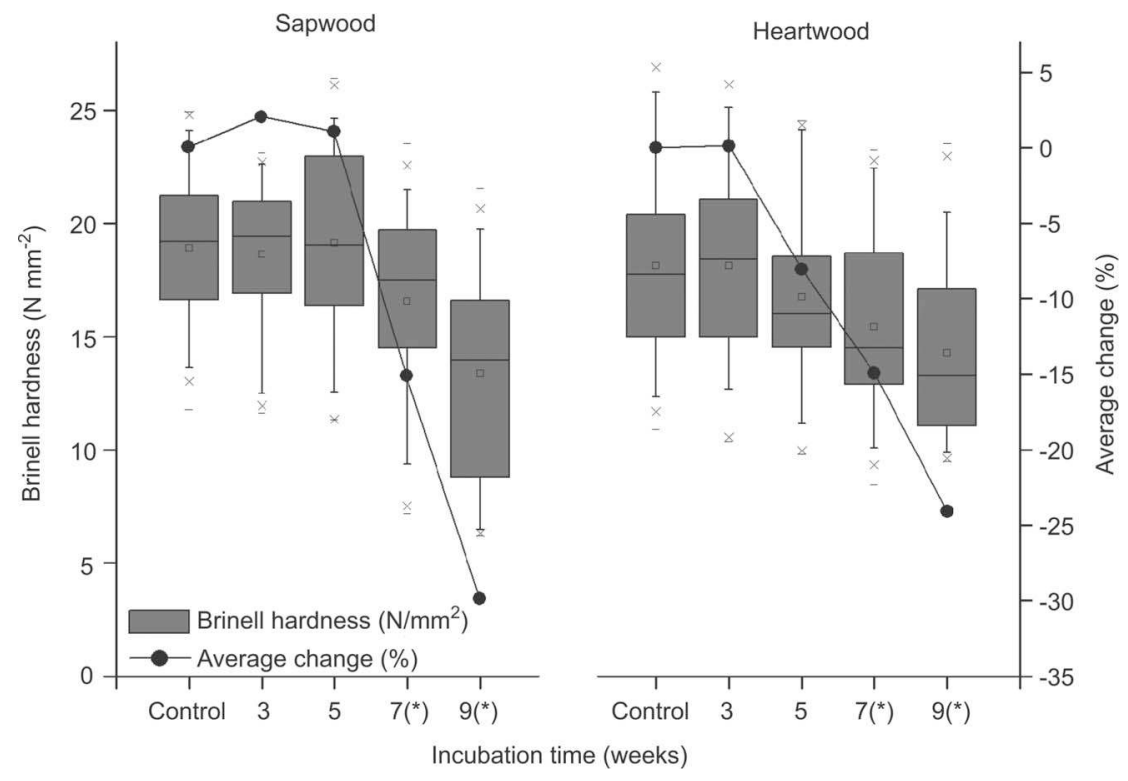

Figure 4 Change of Brinell hardness in Norway spruce after different incubation periods with white rot fungus Physisporinus vitreus. All data from top, bottom, left, and right specimen side are included. *Significant difference compared to control.

heterogeneous colonization of $P$. vitreus in the substrate. Consequently, the bottom areas of the specimen were significantly more affected than the top surfaces (Figures 1 and 5). The greatest reduction in Brinell hardness values was recorded after 9 weeks at the bottom of the sapwood specimen $(-45.2 \%)$.

Minor increases in Brinell hardness can be explained as normal oscillation of the measurement data that results from natural material heterogeneity and the earlywood/latewood distribution at the measurement spot.

\section{Nanoindentation}

Indentations were selectively performed in areas of visible fungal activity. The indenter tip was placed close to hyphal tunneling, cavities, and notches to record the effect of enzymatic degradation in the proximity of hyphal growth (Figure 6).

No clear influence of fungal activity on the nanoindentation data was found over a period of 9 weeks of incubation with $P$. vitreus (Figure 7). The average MOE and hardness for the heartwood control samples was measured to be

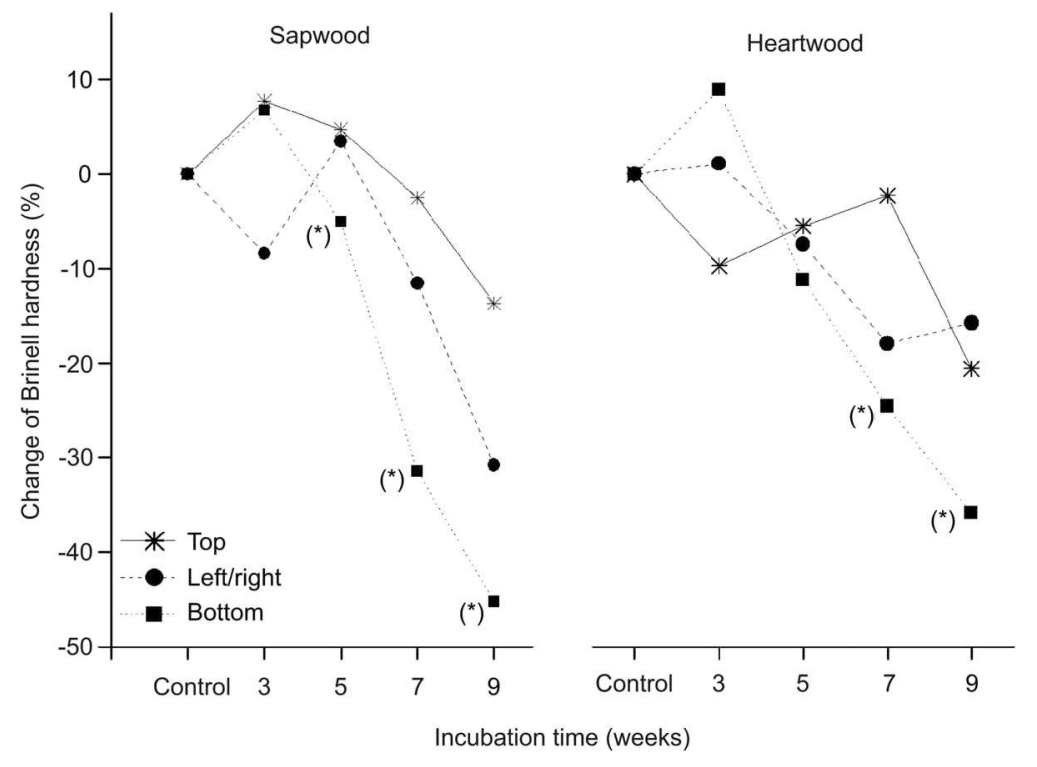

Figure 5 Percentage changes of Brinell hardness according to surface orientation during incubation. *Significant difference between top and bottom specimens. 


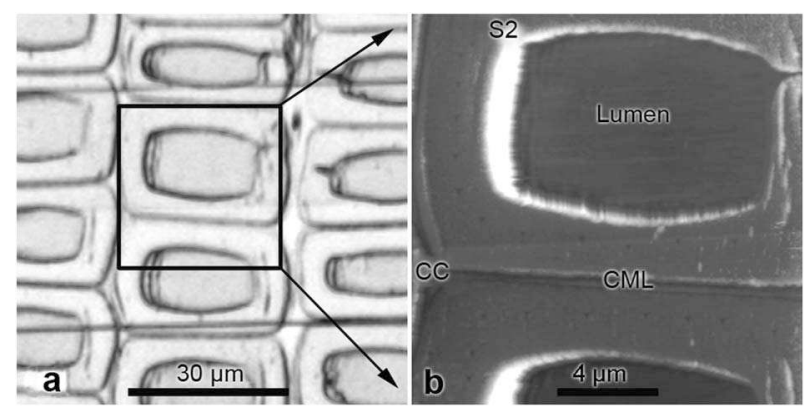

Figure 6 (a) Reflected light microscope micrograph of a polished cross-section of epoxy-resin embedded specimen. (b) Hysitron scanning image of wood cell wall after indentation testing. Note the indentation marks in the secondary cell walls. CC, cell corner; CML, compound middle lamella; S2, secondary cell wall. Both micrographs are from cuts after 5 weeks incubation.

$19.2 \pm 9.6 \%$ and $0.48 \pm 6.1 \% \mathrm{GPa}$, respectively. These values are somewhat comparable with data obtained by Wimmer et al. (1997) and Gindl et al. (2002). Between 3 and 9 weeks incubation, MOE and hardness oscillated between 19.4$20.3 \mathrm{GPa}$ and $0.47-0.53 \mathrm{GPa}$, respectively.

As explained above, hardness is strongly influenced by the lignin content of the cell wall. Consequently, it can be expected that local delignification reduces the hardness within the cell wall. But apparently, the absolute changes in lignin content were too low for detection with nanoindentation measurements.

Nanoindentation evaluates only a very limited area within the tracheid cell wall, and hence large coefficients of variation $(\mathrm{CV})$ can be expected. However, the CV increased with longer incubation times to $10 \%$. This can be interpreted as an increasing heterogeneity of the cell wall matrix with increasing incubation times.

The MOE determined with nanoindentation corresponds to an MOE in compression. Therefore, one could assume that the MOE should clearly decrease in areas with a certain amount of delignification. But according to Bergander and Salmén (2002), delignification plays a subordinate role in this case, because lignin MOE is very low $(2.0 \mathrm{GPa})$ in com-
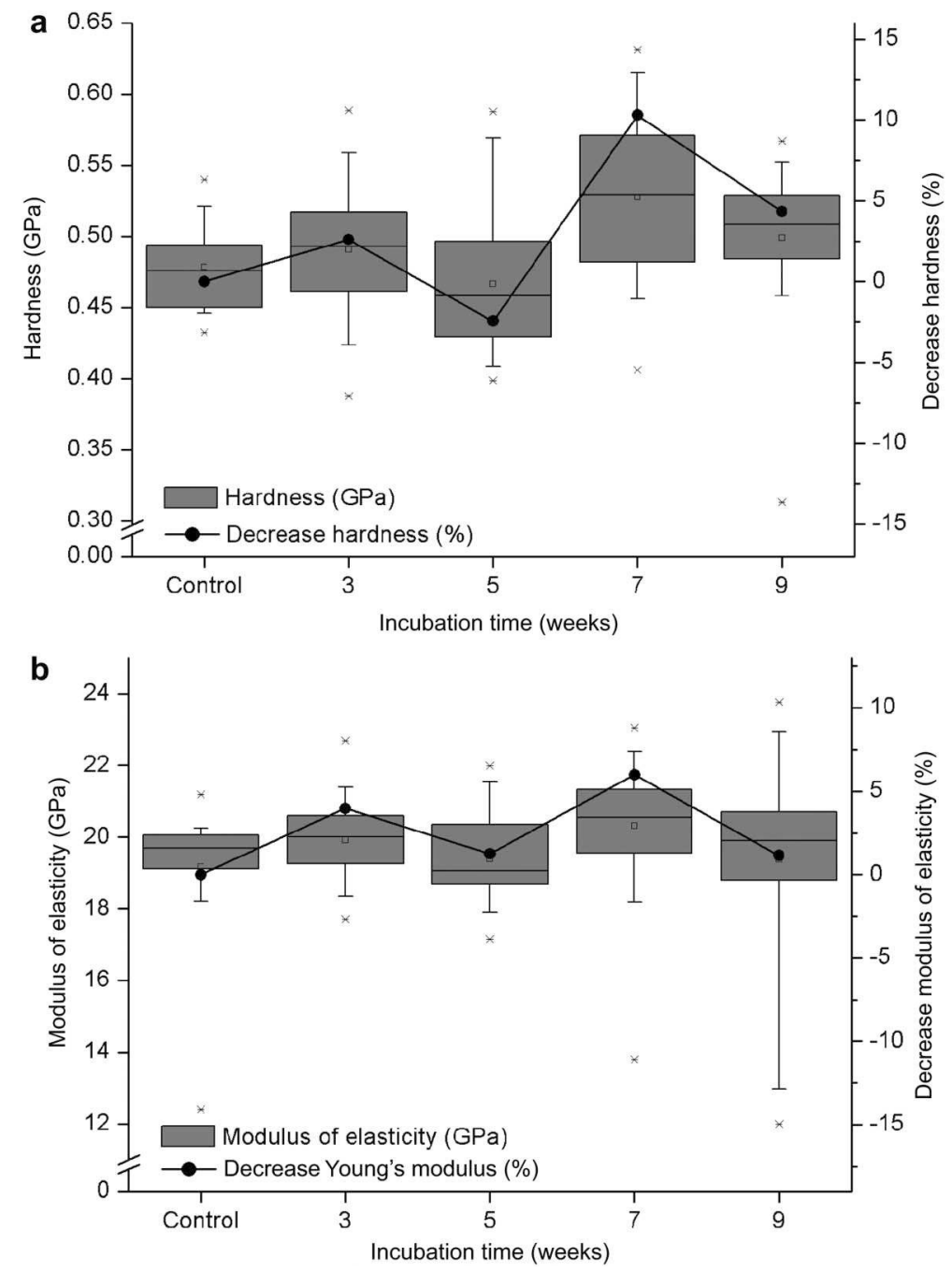

Figure 7 ( $a, b)$ Nanoindentation hardness and reduced modulus of elasticity (MOE) in secondary walls of latewood tracheids in Norway spruce wood incubated with Physisporinus vitreus. 
parison to hemicelluloses $(7.0 \mathrm{GPa})$ and cellulose $(167.5$ $\mathrm{GPa}$ ). Instead, the MOE is directly proportional to the microfibril angle (MFA) as suggested by Gindl and Schöberl (2004) and Wu et al. (2009). However, MFA measurements were not conducted in the present study because all specimens originated from a longitudinal sequence in the same board.

\section{Conclusions}

Cellular UMSP measurements showed that the white rot fungus Physisporinus vitreus induces selective delignification and simultaneous degradation in latewood tracheids of Norway spruce wood. The method allows detecting discreet changes of lignin content, caused by a white rot fungus. The effect is time-dependent and clearly visible after incubation times between 7 and 9 weeks. The coexistence of two lignolytic systems of $P$. vitreus can be confirmed by UMSP. The reduction of the Brinell hardness was only significant after 7 and 9 weeks of incubation. A good correlation between Brinell hardness and the progress of delignification was found. The results of nanoindentation were not as consistent as the results of Brinell hardness. The reproducibility of this method proved to be low due to the heterogeneity of the cell wall, which is changing during degradation. An in-depth analysis of chemical alterations induced by the enzymatic activity of $P$. vitreus will be the subject of the second article of this series (Lehringer et al. 2011).

\section{Acknowledgements}

We would like to thank Dr. J. Michler, Jessica Parsons, and Kombaiah Boopathy for their great support during nanoindentation measurements at Empa Thun. Moreover, we would like to express our gratitude to Markus Heeb (Empa St. Gallen) for his valuable assistance during laboratory work. We also gratefully acknowledge the professional contribution of Prof. F.W.M.R. Schwarze during intensive discussions and proofreading. The present study emerged from the research project CTI.8593.1 LSPP-LS 'Bioincising of conifer wood with Physisporinus vitreus to improve its treatability for a range of wood preservation and modification methods'. The authors express their gratitude to the Swiss CTI (Innovation Promotion Agency) for financial support.

\section{References}

Adusumalli, R.B., Mook, W.M., Passas, R., Schwaller, P., Michler, J. (2010) Nanoindentation of single pulp fibre cell walls. J. Mater. Sci. 45:2558-2563.

Bauch, J., Seehann, G., Fitzner, H. (1976) Microspectrophotometrical investigations on lignin of decayed wood. Mat. Org. Beiheft $3: 141-152$.

Bergander, A., Salmén, L. (2002) Cell wall properties and their effects on the mechanical properties of fibers. J. Mater. Sci. 37:151-156.

Blanchette, R.A., Otjen, L., Effland, M.J., Eslyn, W.E. (1985) Changes in structural and chemical components of wood delignified by fungi. Wood Sci. Technol. 19:35-46.
EN 1534 (2000). Wood and parquet flooring - Determination of resistance to indentation (Brinell) - Test method. CEN European Committee for Standardization.

Fergus, B.J., Procter, A.R., Scott, J.A.N., Goring, D.A.I. (1969) The distribution of lignin in sprucewood as determined by ultraviolet microscopy. Wood Sci. Technol. 3:117-138.

Gindl, W., Schöberl, T. (2004) The significance of the elastic modulus of wood cell walls obtained from nanoindentation measurements. Compos. A Appl. Sci. Manuf. 5:1345-1349.

Gindl, W., Gupta, H.S., Grünwald, C. (2002) Lignification of spruce tracheid secondary cell walls related to longitudinal hardness and modulus of elasticity using nano-indentation. Can. J. Bot. 80: 1029-1033.

Gindl, W., Gupta, H.S., Schöberl, T., Lichtenegger, H.C., Fratzl, P. (2004) Mechanical properties of spruce wood cell walls by nanoindentation. Appl. Phys. A Mater. Sci. Process. 79: 2069-2073.

Hakala, T.K., Lundell, T., Galkin, S., Maijala, P., Kalkkinen, N., Hatakka, A. (2005) Manganese peroxidases, laccases and oxalic acid from the selective white-rot fungus Physisporinus rivulosus grown on spruce wood chips. Enzyme Microb. Technol. 36: 461-468.

Irbe, I., Noldt, G., Koch, G., Andersone, I., Andersons, B. (2006) Application of scanning UV microspectrophotometry for the topochemical detection of lignin within individual cell walls of brown-rotted Scots pine (Pinus sylvestris L.) sapwood. Holzforschung 60:601-607.

Kim, G.H., Son, D.S., Kim, J.J. (2005) Fungi colonizing Douglasfir in cooling towers: identification and their decay capabilities. Wood Fiber Sci. 37:638-642.

Kim, J.S., Lee, K.H., Cho, C.H., Koch, G., Kim, Y.S. (2008) Micromorphological characteristics and lignin distribution in bamboo (Phyllostachys pubescens) degraded by the white rot fungus Lentinus edodes. Holzforschung 62:481-487.

Kleist, G., Seehann, G. (1997) Colonization patterns and topochemical aspects of sap streak caused by Stereum sanguinolentum in Norway spruce. Eur. J. Forest Pathol. 27:351-361.

Kleist, G., Schmitt, U. (1999) Evidence of accessory components in vessel walls of Sapelli heartwood (Entandophragma cylindricum) obtained by transmission electron microscopy. Holz Roh Werkst. 57:93-95.

Kleist, G., Schmitt, U. (2001) Characterisation of a soft rot-like decay pattern caused by Coniophora puteana (Schum.) Karst. in Sapelli wood (Entandrophragma cylindricum Sprague). Holzforschung 55:573-578.

Koch, G., Kleist, G. (2001) Application of scanning UV microspectrophotometry to localise lignins and phenolic extractives in plant cell walls. Holzforschung 55:563-567.

Konnerth, J., Harper, D., Lee, S.H., Rials, T.G., Gindl, W. (2008) Adhesive penetration of wood cell walls investigated by scanning thermal microscopy (SThM). Holzforschung 62:91-98.

Konnerth, J., Gierlinger, N., Keckes, J., Gindl, W. (2009) Actual versus apparent within cell wall variability of nanoindentation results from wood cell walls related to cellulose microfibril angle. J. Mater. Sci. 44:4399-4406.

Konnerth, J., Eiser, M., Jäger, A., Bader, T.K., Hofstetter, K., Follrich, J., Ters, T., Hansmann, C., Wimmer, R. (2010) Macro- and micro-mechanical properties of red oak wood (Quercus rubra L.) treated with hemicellulases. Holzforschung 64:447-453.

Lee, S.H., Wang, S., Pharr, G.M., Kant, M., Penumadu, D. (2007) Mechanical properties and creep behavior of lyocell fibers by nanoindentation and nano-tensile testing. Holzforschung 61: 254-260. 
Lehringer, C., Gierlinger, N., Koch, G. (2008) Topochemical investigation on tension wood fibres of Acer spp., Fagus sylvatica L. and Quercus robur L. Holzforschung 62:255-263.

Lehringer, C., Richter, K., Schwarze, F.W.M.R., Militz, H. (2009) A review on promising approaches for liquid permeability improvement in softwoods. Wood Fiber Sci. 41:373-385.

Lehringer, C., Hillebrand, K., Richter, K., Arnold, M., Schwarze, F.W.M.R., Militz, H. (2010) Anatomy of bioincised Norway spruce wood. Int. Biodeter. Biodegrad. 64:346-355.

Lehringer, C., Saake, B., Živković, V., Richter, K., Militz, H. (2011) Effect of Physisporinus vitreus on wood properties of Norway spruce. Part 2: aspects of microtensile strength and chemical changes. Holzforschung 65:721-727.

Liese, W. (1970) Ultrastructural aspects of woody tissue disintegration. Annu. Rev. Phytopathol. 8:231-257.

Mai, C., Kües, U., Militz, H. (2004) Biotechnology in the wood industry. Appl. Microbiol. Biotechnol. 63:477-494.

Morrell, J.J., Zabel, R.A. (1985) Wood strength and weight losses caused by soft-rot fungi isolated from treated southern pine utility poles. Wood Fiber Sci. 17:132-143.

Oliver, W.C., Pharr, G.M. (1992) Improved technique for determining hardness and elastic modulus using load and displacement sensing indentation experiments. J. Mater. Res. 7:1564-1580.

Oliver, W.C., Pharr, G.M. (2004) Measurement of hardness and elastic modulus by instrumented indentation: advances in understanding and refinements to methodology. J. Mater. Res. 19:320.

Prislan, P., Koch, G., Cufar, K., Gričar, J., Schmitt, U. (2009) Topochemical investigations of cell walls in developing xylem of beech (Fagus sylvatica L.). Holzforschung 63:482-490.

Reinprecht, L., Novotná, H., Stefka, V. (2007) Density profiles of spruce wood changed by brown-rot and white-rot fungi. Wood Res. Slovakia 52:17-28.

Rypacek, V. Biologie holzzerstörender Pilze. Gustav Fischer Verlag, Jena, 1966.

Schmidt, O. Wood and Tree Fungi. Springer Verlag, Berlin/Heidelberg, 2006.

Schwarze, F.W.M.R. (2007) Wood decay under the microscope. Fungal Biol. Rev. 21:133-170.

Schwarze, F.W.M.R., Landmesser, H., Zgraggen, B., Heeb, M. (2006) Permeability changes in heartwood of Picea abies and
Abies alba induced by incubation with Physisporinus vitreus. Holzforschung 60:450-454.

Schwarze, F.W.M.R., Spycher, M., Fink, S. (2008) Superior wood for violins - wood decay fungi as a substitute for cold climate. New Phytol. 179:1095-1104.

Sonderegger, W. and P. Niemz (2001). Determination of Brinell hardness on MDF and HDF panel boards by differential measurement of indentation depth (Untersuchungen zur Bestimmung der Brinellhärte an MDF- und HDF-Platten mittels Wegmessung) Int. report ETHZ/HW-HP-LZfP Nr. 3:1-10.

Spurr, A.R. (1969) A low-viscosity epoxy resin embedding medium for electron microscopy. J. Ultrastruct. Res. 26:31-43.

Stöckel, F., Konnerth, J., Kantner, W., Moser, J., Gindl, W. (2010) Tensile shear strength of UF- and MUF-bonded veneer related to data of adhesives and cell walls measured by nanoindentation. Holzforschung 64:337-342.

Unbehaun, H., Dittler, B., Kühne, G., Wagenführ, A. (2000) Investigation into the biotechnological modification of wood and its application in the wood-based material industry. Acta Biotechnol. 20:305-312.

van Acker, J., Stevens, M. (1996) Laboratory culturing and decay testing with Physisporinus vitreus and Donkioporia expansa originating from identical cooling tower environments show major differences. Int. Res. Group Wood Pres. IRG/WP/10184:8.

Wang, S., Lee, S.H., Tze, W.T.Y., Rials, T., Pharr, G.M. (2006) Nanoindentation as a tool for understanding nano-mechanical properties of wood cell wall and biocomposites. In: TAPPI International Conference on Nanotechnology, Atlanta, GA, USA. pp. $152-158$.

Whetten, R., Sederoff, R. (1995) Lignin biosynthesis. Plant Cell 7:1001-1013.

Wimmer, R., Lucas, B.H., Tsui, T.Y., Oliver, W.C. (1997) Longitudinal hardness and Young's modulus of spruce tracheid secondary walls using nanoindentation technique. Wood Sci. Technol. 31:131-141.

Wu, Y., Wang, S., Zhou, D., Xing, C., Zhang, Y. (2009) Use of nanoindentation and silviscan to determine the mechanical properties of 10 hardwood species. Wood Fiber Sci. 41:64-73.

Received July 16, 2010. Accepted September 28, 2010.

Previously published online January 13, 2011. 